\title{
Neurofibrillary tangles in dementia pugilistica are ubiquitinated
}

\author{
G E Dale, P N Leigh, P Luthert, B H Anderton, G W Roberts
}

Neurology

P N Leigh

Department of

Neuropathology

P Luthert

Department of

Neuroscience

B H Anderton

Department of

Anatomy and Cell

Biology, St Mary's

Hospital Medical

School, London

G W Roberts

Correspondence to:

Dr Roberts,

Department of Anatomy and

Cell Biology, St Mary's

Cell Biology, St Mary's

Praed St, London W2 1PG, UK

Received 25 January 1990 and in revised form

10 April 1990.

Accepted 15 June 1990

\begin{abstract}
Department of Immunology, St George's Hospital Medical School,

London

G E Dale

Institute of

Psychiatry, London

Department of

Abstract

Ubiquitin, a protein thought to be involved in the ATP-dependent nonlysosomal degradation of abnormal proteins, has already been identified as a component of neurofibrillary tangles in Alzheimer's disease. We have examined ubiquitin immunoreactivity in a unique collection of brains from 16 ex-boxers including 11 with dementia pugilistica. Neurofibrillary tangles of dementia pugilistica were labelled with an affinity purified antiserum to ubiquitin, and BF10, a monoclonal antibody to a neurofilament epitope.
\end{abstract}

Dementia pugilistica or punch drunk syndrome is a clinical entity associated with the repeated head trauma sustained during boxing. ${ }^{1} \mathrm{~A}$ characteristic pattern of brain damage was described in an extensive neuropathological study of fifteen retired boxers. ${ }^{2}$ Damage to the septum pellucidum, scarring of the cerebellar and cerebral cortex and loss of pigmented neurons in the substantia nigra were seen in many cases. Neurofibrillary tangles, morphologically identical to those seen in Alzheimer's disease, were also seen in large numbers in cases of dementia pugilistica, particularly in the temporal lobe. In contrast to the neuropathological picture seen in Alzheimer's disease, neuritic senile plaques are typically few or absent.

The tangles of dementia pugilistica share antigens with Alzheimer tangles. In a recent study of eight of the cases described by Corsellis et $a l^{2}{ }^{2}$ antibodies raised against Alzheimer paired helical filaments and neurofilaments were shown to label pugilistica tangles as well as Alzheimer tangles. ${ }^{3}$ Alzheimer tangles have been shown to contain epitopes of ubiquitin, a protein believed to play a role in the removal of abnormal and short-lived proteins from the cell. ${ }^{4-6} \mathrm{We}$ were interested in investigating whether ubiquitin is a component of tangles in dementia pugilistica.

\section{Patients and methods}

Brain material was obtained from sixteen cases, all of whom were retired boxers except one, who was a young man of 22 who died in the ring. Ten of the cases had been described by Corsellis $e t a l^{2}$ and there were five additional cases. The series included both professional and amateur boxers (table). Frontal and/or temporal lobe was available from each case. Clinical histories indicated that eleven of the sixteen cases suffered from dementia pugilistica (table).

Sections $(20 \mu \mathrm{m}$ thick) of formalin-fixed paraffin-embedded brain material were stained (a) with an affinity purified rabbit antiserum to ubiquitin (as described previously ${ }^{7}$ ) or $(b)$ with a monoclonal antibody, BF10, which labels a phosphorylated epitope of the medium weight neurofilament protein, NF-M. BF10 has already been shown to label tangles in both Alzheimer's disease and

Table Case details of boxers showing immunolabelling of tangles with anti-ubiquitin BF10 and silver stain

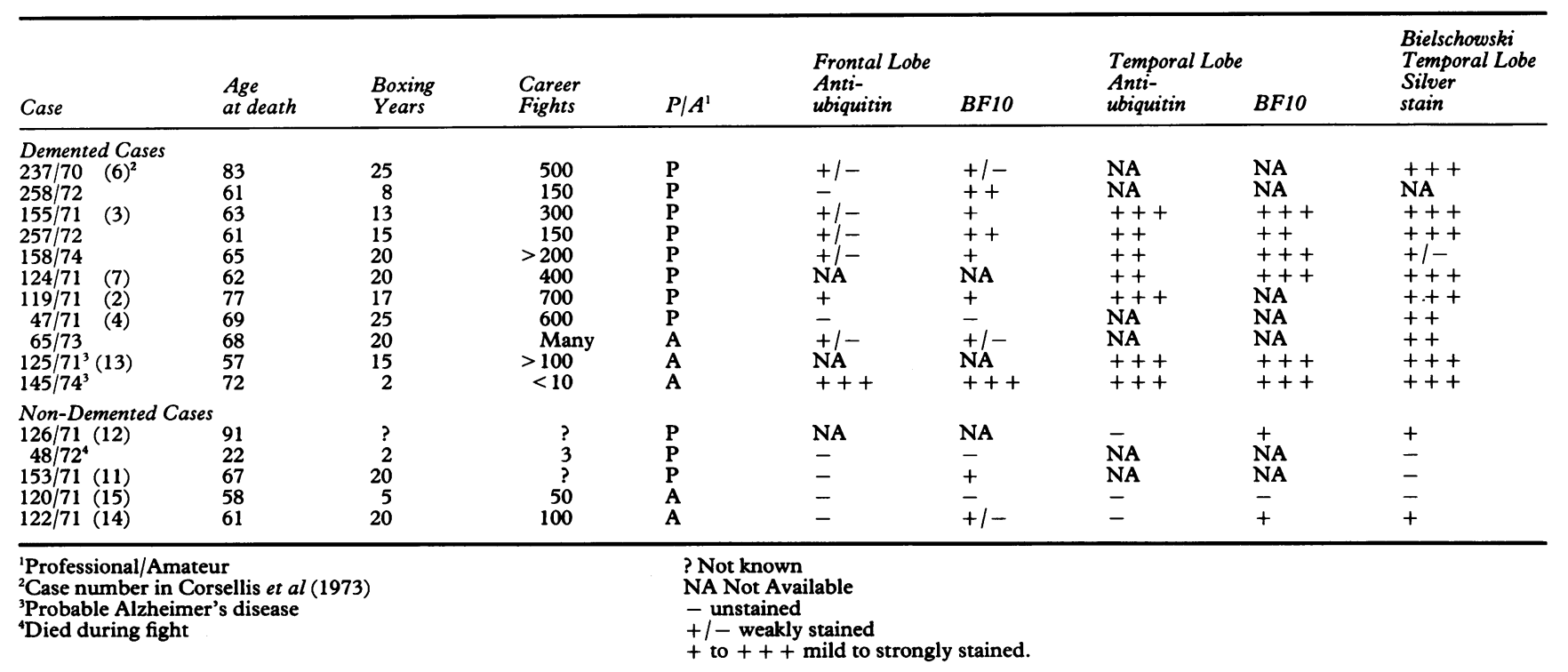


dementia pugilistica. $^{38}$ Immunohistochemistry was performed using the streptavidinbiotin-horse radish peroxidase system, employing diaminobenzidine as the chromogen. A temporal lobe section from a case of Alzheimer's disease was included in each experiment as a positive control for the antibodies. Primary antibody was excluded from another section of Alzheimer brain to eliminate the possibility of non-specific reactivity.

\section{Results}

Brains from all but one of the demented exboxers showed some evidence of neurofibrillary tangle formation following staining with BF10 (fig 1) and also, in most cases, with anti-ubiquitin (fig 2) (table). BF10 generally labelled more tangles and with greater intensity than anti-ubiquitin. Of the five non-demented ex-boxers, three showed BF10-labelling of tangles, but tangles were

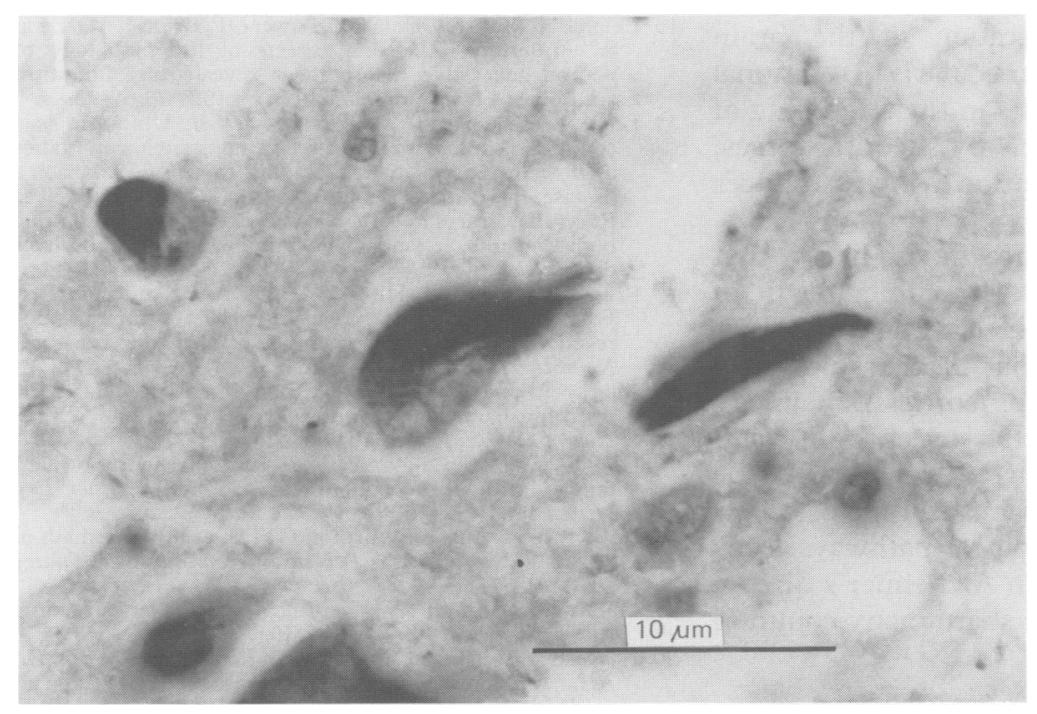

Figure 1 Neurofibrillary tangle in temporal lobe section from a case of dementia pugilistica (case 158/74) labelled with BF10, a monoclonal antibody specific for the medium-weight neurofilament protein, NF-M. Scale bar $10 \mu \mathrm{m}$.

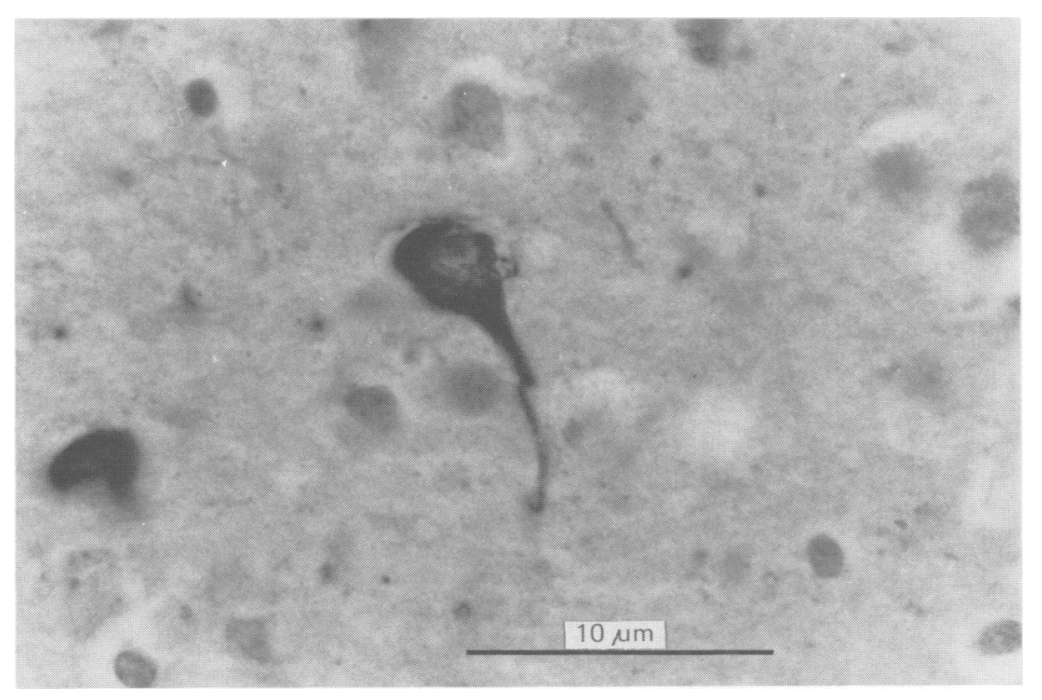

Figure 2 Neurofibrillary tangle in temporal lobe section from a case of dementia pugilistica (case 155/71) labelled with affinity-purified anti-ubiquitin. Scale bar $10 \mathrm{\mu m}$. not visualised with anti-ubiquitin (table). Tangles labelled with BF10 were less numerous in the nondemented cases than in those who had been demented. No relationship between the degree of neuropathology and the number of years of boxing, the number of fights or the professional/amateur status of the ex-boxers was discernible. Some cases showed evidence of senile plaque formation, although plaques tended to be few in number and of an "immature" type. In two cases who were demented (125/71 and 145/ 74), however, a large number of classical senile plaques and tangles were evident, suggesting Alzheimer's disease.

\section{Discussion}

We have now shown that ubiquitin, which is known to be a component of Alzheimer's tangles, ${ }^{4-6}$ is present in the neurofibrillary tangles of dementia pugilistica. Ubiquitin-labelling of tangles in a single case of dementia pugilistica has been noted previously, ${ }^{9}$ although no case details were given in that study. Ubiquitin is, at present, the only protein consistently detected in inclusions associated with several neurodegenerative diseases including Lewy bodies in Parkinson's disease ${ }^{10}$ anterior horn cell inclusions in motor neuron disease, ${ }^{711} 12$ Pick bodies of Pick's disease ${ }^{1314}$ in addition to the tangles of Alzheimer's disease and dementia pugilistica.

We have shown that in many cases of dementia pugilistica more tangles are evident following labelling with $\mathrm{BF} 10$, a monoclonal antibody to a neurofilament epitope, than with anti-ubiquitin. The occurrence and immunoreactivity of tangles did not appear to correlate with the length of the boxers' careers, the number of fights or their professional/amateur status. Interestingly, in three of the five non-demented ex-boxers studied, tangles were identified following BF10 staining but were not detectable with antiubiquitin. The tangles tended to be less numerous in the non-demented than demented cases. Ubiquitin thus appears to be a component of only a sub-population of tangles in dementia pugilistica. A similar heterogeneity in tangle populations has also been reported in Alzheimer's disease. Brion et al ${ }^{15}$ showed that only about half of the Alzheimer tangles identified by labelling with antiserum to paired helical filaments were labelled with anti-ubiquitin, even though the majority of isolated SDS-insoluble tangles were ubiquitin labelled.

Tangles labelled with anti-ubiquitin, which labels ubiquitin-protein conjugates, may identify cells where abnormal proteins conjugated to ubiquitin have not been successfully removed by the ubiquitin-dependent proteolytic system. The accumulation of these conjugates may be detrimental to cell function or may simply be indicative of a dying cell. It is possible that dementia may result from the dysfunction of cells bearing ubiquitinated tangles. Cells containing tangles which do not label with anti-ubiquitin may be successfully 
processing aberrant proteins and thus maintaining some degree of normal function.

This and a previous immunohistochemical study ${ }^{3}$ highlight common constituent proteins in neurofibrillary tangles of Alzheimer's disease and dementia pugilistica. One of the hallmarks for the diagnosis of Alzheimer's disease is the presence of neuritic (PHF and + ubiquitin - containing) plaques with an A4/ $\beta$ protein core. These classic senile plaques, however, are few or absent in most cases of dementia pugilistica, suggesting that the process of tangle formation can occur without neuritic plaque formation. Neurofibrillary tangles occur in the absence of neuritic amyloid plaques in other conditions including sub-acute sclerosing panencephalitis $^{16}$ and 18q-syndrome. ${ }^{17}$ Deposits of A4 protein, a component of amyloid, have recently been seen immunohistochemically in cases of dementia pugilistica following pretreatment of paraffin sections with formic acid, ${ }^{18}$ even though this amyloid is not visible using congo red or standard silver staining techniques.

Brain damage to boxers results from acceleration and deceleration of the brain within the skull, particularly rotational acceleration, which results in the stretching of neurons and blood vessels by sheering forces, as well as linear acceleration which produces focal lesions. ${ }^{19}$

In dementia pugilistica it is likely that tangle formation occurs as a direct result of these damaging forces on neuronal processes. It has been suggested that head trauma may be a factor in the development of Alzheimer's disease, ${ }^{20}$ although genetic susceptibility and environmental toxins currently appear to be more favoured as putative causal factors. It is plausible that the aetiological pathways leading to tangle formation in Alzheimer's disease and dementia pugilistica share many common features.
1 Martland HS. Punch Drunk. J Am Med Assoc 1928;91:1103-7.

2 Corsellis JAN, Bruton CJ, Freeman-Brown D. The aftermath of boxing. Psychol Med 1973;3:270-303.

3 Roberts GW. Immunocytochemistry of neurofibrillary tangles in dementia pugilistica and Alzheimer's disease: Evidence for a common genesis. Lancet 1988;ii:1456-8.

4 Cole GM, Timiras PS. Ubiquitin-protein conjugates in Alzheimer's lesions. Neurosci Lett 1987;79:207-12.

5 Mori $\mathrm{H}$, Kondo J, Ihara Y. Ubiquitin is a component of paired helical filaments in Alzheimer's disease. Science 1987;235:1641-4.

6 Perry G, Friedman R, Shaw G, Chau V. Ubiquitin is detected in neurofibrillary tangles and senile plaque neurites of Alzheimer's disease brains. Proc Natl Acad Sci (USA) 1987;84:3033-6.

7 Leigh PN, Anderton GH, Dodson A, Gallo J-M, Swash M, Power DM. Ubiquitin deposits in anterior horn cells in Power DM. Ubiquitin deposits in anterior horn cells in
motor neurone disease. Neurosci Lett 1988;93:197-203.

$8 \mathrm{Kahn}$ J, Anderton BH, Gibb WRG, Lees AJ, Wells FR, Marsden CD. Neuronal filaments in Alzheimer's, Pick's
and Parkinson's disease. N Engl J Med 1985;313:520-1.

9 Lennox G, Lowe J, Morrell K, Landon M, Mayer RJ. Ubiquitin is a component of neurofibrillary tangles in a variety of neurodegenerative diseases. Neurosci Lett 1988;94:211-7.

10 Kuzuhara S, Mori H, Izumiyama N, Yoshimura M, Ihara Y. Lewy bodies are ubiquitinated. Acta Neuropathol (Berl) 1988;75:345-53.

11 Kato T, Katagiri T, Hirano T, Kawanami T, Sasaki H. Lewy body-like inclusions in sporadic motor neuron disease are ubiquitinated. Acta Neuropathol (Berl) 1989;77:391-6.

12 Lowe J, Lennox G, Jefferson D, et al. A filamentous inclusion body within anterior horn neurones in motor inclusion body within anterior horn neurones in motor neurone disease defined by immunocytochemical
isation of ubiquitin. Neurosci Lett 1988;94:203-10.

13 Leigh PN, Probst A, Dale GE, Power DP, Brion JP, Dodson $\mathrm{A}$, Anderton $\mathrm{BH}$. New aspects of the pathology of neurodegenerative disorders as revealed by ubiquitin antibodies. Acta Neuropathol (Berl) 1989;79:61-72.

14 Lowe J, Blanchard A, Morrell $\mathrm{K}$, et al. Ubiquitin is a common factor in intermediate filament inclusion bodies of diverse type in man, including those of Parkinson's disease, Pick's disease, and Alzheimer's disease, as well as Rosenthal Fibres in cerebellar astrocytomas, cytoplasmic bodies in muscle, and mallory bodies in alcoholic liver disease. J Pathol 1988;155:9-15.

15 Briot J-P, Power D, Hue D, Couck AM, Anderton BH, Flament-Durand J. Heterogeneity of ubiquitin immunoFlament-Durand J. Heterogeneity of ubiquitin immunoreactivity in neurofibrillary tang

16 Mandybur TI. The distribution of Alzheimer's neurofibrillary tangles and gliosis in chronic SSPE. Neuropathol Exp Neurol 1989;48:338.

17 Halliday WC, Chudley AE. 18q-syndrome neurofibrillary tangles without neuritic plaques. I Neuropathol Exp Neurol 1989;48:308.

18 Roberts GW, Allsop D, Bruton C. The occult aftermath of boxing. (May Issue) J Neurol Neurosurg Psychiatry 1990;53:373-8.

19 Guterman A, Smith RW. Neurological sequelae of boxing. Sports Medicine. 1987;4:194-210.

20 Heyman A, Wilkinson WE, Stafford JA, Helms MJ, Sigman AH, Weiningon epidemiological aspects. Ann Neurol 1984;15:335-41. 